\title{
Transplante terapêutico de córnea: resultados prolongados de série de casos
}

\author{
Long-term follow-up of a case series of therapeutic corneal transplant
}

\author{
Flávia Chaves de Oliveira ${ }^{1}$ \\ Paulo Elias Correa Dantas ${ }^{2}$ \\ Erlan Stephan De Marco ${ }^{3}$ \\ Adriana Chaves de Oliveira ${ }^{4}$ \\ Maria Cristina Nishiwaki-Dantas ${ }^{5}$
}

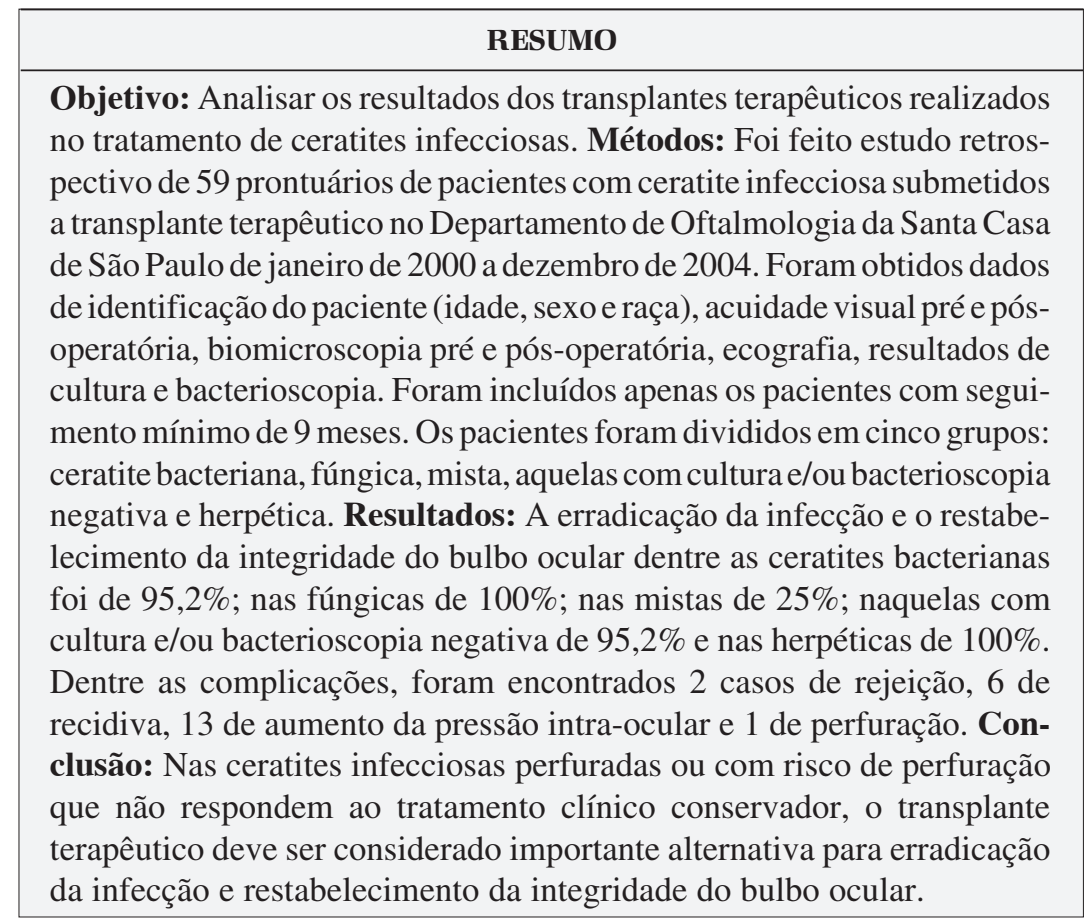

Descritores: Transplante de córnea; Ceratoplastia penetrante; Ceratities/cirurgia; Ceratite/ microbiologia; Acuidade visual; Infecções oculares/cirurgia

\section{INTRODUÇÃO}

Classicamente, os transplantes de córnea podem cumprir finalidade óptica, com o objetivo de promover a visão; terapêutica, para controlar doença corneal refratária a tratamento clínico, e tectônica para restabelecer a integridade estrutural do bulbo ocular ${ }^{(1)}$.

Certas características marcam o transplante terapêutico. O fato de ser realizado, na maioria das vezes, em caráter de urgência, relega a reabilitação da acuidade visual a um plano secundário. Outro fator importante diz respeito à qualificação do tecido doador. Em geral, córneas com baixa contagem de células endoteliais e/ou opacidades cicatriciais, que normalmente não seriam utilizadas com finalidade óptica, podem ser utilizadas para transplante terapêutico, tornando a disponibilidade de córneas doadoras maior ${ }^{(1)}$.

Ceratite infecciosa resistente a tratamento clínico é a principal indicação de transplante terapêutico(2). Trata-se de doença grave cuja evolução clínica depende do agente agressor e da resistência do hospedeiro. Apesar dos avanços na terapia antimicrobiana, antifúngica e antiviral, a ceratite infecciosa pode progredir rapidamente em extensão e profundidade, com afina- 
mentos e perfurações ${ }^{(2)}$. Quando, apesar da máxima terapia medicamentosa, a infecção progride com perfuração ou risco iminente de perfuração, o transplante terapêutico torna-se mandatório para remoção do inóculo infeccioso e restabelecimento da integridade do bulbo ocular ${ }^{(3)}$.

Estudos mostram que a necessidade de cirurgia para erradicar a infecção na ceratite bacteriana ( 3 a $6 \%$ ) é menor do que na ceratite fúngica (18 a 29\%) $)^{(4-6)}$. É fato notório termos opções de antibioticoterapia tópica para tratamento das infecções bacterianas e antibióticos cada vez mais potentes e com menor possibilidade de desenvolver resistência bacteriana. Para as ceratites fúngicas, são menores as opções de antifúngicos tópicos e, além disso, o diagnóstico é geralmente mais tardio, a identificação do fungo no laboratório é mais difícil e o tratamento específico muitas vezes é iniciado quando a doença está em fase avançada ${ }^{(4-7)}$.

Pseudomonas aeruginosa e Staphylococcus s $\mathrm{p}^{(3,8)}$ são as bactérias mais freqüentemente isoladas nas ceratites bacterianas e, considerando-se a erradicação do processo infeccioso e a manutenção da integridade do bulbo ocular, resultados de estudos mostram que a cirurgia pode ser considerada eficaz em $96 \%^{(9)}$ a $100 \%$ dos casos.

$\mathrm{Na}$ ceratite fúngica, os índices de cura variam entre $86 \%$ e $100 \%(4,8,10-12)$.

O transplante terapêutico pode ser indicado também na ceratite herpética ativa ou inativa. Geralmente são casos de ceratite estromal grave com necrose, ulceração e até perfuração. Com o uso de terapia antiviral sistêmica profilática o prognóstico cirúrgico tem melhorado sensivelmente ${ }^{(13-16)}$.

Deve-se evitar outros procedimentos, como remoção do cristalino, exceto se houver ruptura da cápsula anterior ${ }^{(1-2,7,16)}$.

A concomitância com a endoftalmite é muitas vezes tratada cirurgicamente, com vitrectomia e injeção intra-vítrea de antibióticos e/ou antifúngicos, com índice de cura em torno de $100 \%{ }^{(17,9)}$.

A transparência do botão corneal transplantado até 12 meses após a cirurgia está fortemente relacionada com o tamanho do enxerto e o agente agressor ${ }^{(1,7)}$. A alta porcentagem de botão transparente é normalmente atingida com enxertos medindo $9,0 \mathrm{~mm}$ ou menos ${ }^{(1,7,16)}$. Na ceratite bacteriana, varia entre $68 \%^{(7)}$ e $73 \%^{(1)}$; na fúngica, de $51 \%^{(7)}$ a $79 \%^{(1,17-18)}$ e na herpética de $36 \%^{(1)}$ a $84 \%{ }^{(13,19)}$.

Complicações após o transplante terapêutico tendem a ser mais freqüentes do que no transplante óptico. $\mathrm{O}$ tamanho da área submetida à trepanação deve ser o menor possível, mas deve englobar toda a área acometida pelo processo infeccioso, o que pode resultar em botões corneais grandes e descentrados, portanto com maior risco de astigmatismo (botão corneal descentrado com sutura no eixo visual) e rejeição (botão corneal muito grande e mais próximo do limbo tem mais possibilidade de desenvolver rejeição) ${ }^{(1,7,9,16)}$.

Outras complicações, como aumento da pressão intra-ocular e catarata, são influenciadas pela gravidade ou intensidade da inflamação na ocasião da cirurgia ${ }^{(1,7,9,16)}$.

No período entre janeiro de 2000 e dezembro de 2004, foram realizados 320 transplantes penetrantes de córnea no Departamento de Oftalmologia da Santa Casa de São Paulo, dos quais $59(18,4 \%)$ foram terapêuticos, feitos em pacientes com diagnóstico de ceratite infecciosa refratárias ao tratamento clínico, com perfuração ou risco iminente de perfuração. $\mathrm{O}$ objetivo deste estudo foi analisar os resultados dos transplantes terapêuticos realizados no tratamento das ceratites infecciosas no Departamento de Oftalmologia da Santa Casa de São Paulo.

\section{MÉTODOS}

Realizamos estudo retrospectivo de 59 prontuários de pacientes com ceratite infecciosa submetidos a transplante terapêutico de córnea no Setor de Córnea e Doenças Externas do Departamento de Oftalmologia da Santa Casa de São Paulo, no período compreendido entre janeiro de 2000 e dezembro de 2004.

Foram obtidos dados demográficos dos pacientes (idade, sexo e raça), diagnóstico e exame oftalmológico, que consistiu de medida da acuidade visual pré e pós-operatória, biomicroscopia pré e pós-operatória, ecografia pré-operatória, resultados de cultura e bacterioscopia. Foram incluídos apenas pacientes com seguimento de, no mínimo, nove meses. Também foram coletadas informações sobre o procedimento cirúrgico, como o tamanho do trépano utilizado para a confecção do botão corneal doador e do leito receptor e outros procedimentos associados, como extração do cristalino.

O diagnóstico de ceratite infecciosa baseou-se na anamnese e quadro clínico-laboratorial. Os 50 casos de ceratite infecciosa bacteriana ou fúngica foram diagnosticados clinicamente pela presença de infiltrado corneal, com ou sem ulceração da superfície. Foi feito estudo microbiológico de todos os 50 casos pela coleta de material do infiltrado corneal com espátula de Kimura para esfregaço em lâmina (corada pelo Gram) e cultura em placas de ágar-sangue $\left(a 37^{\circ} \mathrm{C}\right.$ ), ágar-chocolate em capnofilia (a $35^{\circ} \mathrm{C}$ ) e ágar-Sabouraud sob temperatura ambiente. Nos nove casos de ceratite herpética, o diagnóstico baseou-se na anamnese e exame clínico. Não foi feita pesquisa laboratorial para diagnóstico de ceratite herpética.

Todos os pacientes com ceratite infecciosa bacteriana ou fúngica foram tratados clinicamente, de acordo com protocolo previamente estabelecido. Casos com infiltrado estromal, após submetidos à coleta de material para identificação do agente agressor, foram tratados com colírios fortificados de cefalosporina (cefalotina $50 \mathrm{mg} / \mathrm{ml}$ ) e aminoglicosídeo (tobramicina ou gentamicina $15 \mathrm{mg} / \mathrm{ml}$ ). A troca do antibiótico era realizada depois de identificado o agente, nos casos em que não havia melhora.

Pacientes com ceratite estromal herpética que apresentavam epitélio íntegro foram tratados com corticosteróide tópico (dexametasona a $0,1 \%$ ou acetato de prednisolona a $1 \%$ ) associado a antiviral sistêmico (aciclovir $800 \mathrm{mg}-2 \mathrm{~g} /$ dia por via oral) e aqueles com ceratite epitelial foram tratados somente com antiviral sistêmico, em dose terapêutica de $2 \mathrm{~g} / \mathrm{dia}$. A dosagem do corticosteróide tópico variou com o grau de inflamação local. 
Foi indicado transplante terapêutico nos casos refratários ao tratamento preconizado, com perfuração ou risco de perfuração.

As córneas utilizadas para transplante terapêutico foram obtidas do Banco de Olhos da Santa Casa de São Paulo. Todas foram mantidas em solução de Optisol por período máximo de 14 dias. Antes da indicação cirúrgica, foi realizado exame ultrasonográfico para avaliar o pólo posterior e afastar a presença de descolamento de retina e para auxiliar no diagnóstico de endoftalmite.

As cirurgias foram realizadas sob anestesia local, usandose a seguinte técnica cirúrgica:

- Devido à hipotonia e ao alto grau de inflamação e infecção, não foi feita a fixação do anel escleral na maior parte dos casos.

- O tamanho do trépano a ser utilizado era calculado de modo a englobar toda a área acometida pelo processo infeccioso. A trepanação do leito receptor foi feita com trépano manual, seguida pela abertura da câmara anterior com bisturi lâmina 11 e completada a retirada do botão corneal com tesoura de córnea. Para retirar o botão, foram utilizadas substâncias viscoelásticas para afastar a íris e o cristalino.

- Sinéquias periféricas foram desfeitas com espátula de ciclodiálise e membranas de fibrina sobre a íris e o cristalino foram removidas com pinça.

- Para prevenir o bloqueio pupilar e o glaucoma secundário, iridectomia periférica era realizada.

- Após a lavagem da câmara anterior com solução salina balanceada, era feita irrigação com antibiótico (cefalotina e gentamicina) ou antifúngico (anfotericina B), com diluição apropriada para uso intra-camerular, de acordo com o diagnóstico clínico e/ou laboratorial.

- Não foi feita remoção do cristalino, mesmo quando opaco, exceto se houvesse lesão da cápsula anterior.

- O tamanho do botão corneal doador era 0,25 a 1,0 mm maior que o leito receptor e era suturado com 16 pontos separados de mononylon 10-0; três casos foram suturados com 12 pontos. Todos os nós das suturas eram sepultados ao final da sutura.

- Antes do curativo oclusivo, foi feita injeção subconjuntival de antibiótico e antiinflamatório (gentamicina e dexametasona).

Após a cirurgia, foram mantidas as medicações usadas no período pré-operatório para controle da infecção.

Os pacientes foram divididos em cinco grupos:

- Grupo 1: ceratite infecciosa com cultura e/ou bacterioscopia negativa

- Grupo 2: ceratite bacteriana

- Grupo 3: ceratite fúngica

- Grupo 4: ceratite mista (bacteriana e fúngica) e

- Grupo 5: ceratite herpética.

A idade média dos pacientes foi de 54,4 anos $\pm 18,2$ (variou de 3 a 85 anos), 66,1\% dos pacientes eram do sexo masculino e $33,8 \%$ do sexo feminino. Em relação à raça, 79,7\% eram brancos, $16,7 \%$ pardos e $3,3 \%$ negros.
Os critérios de sucesso do transplante terapêutico foram a cura do processo infeccioso após a cirurgia e o restabelecimento da integridade do bulbo ocular.

Complicações como recidiva de infecção, rejeição, aumento da pressão intra-ocular e catarata foram identificadas e anotadas.

\section{RESULTADOS}

A acuidade visual pré-operatória variou de ausência de percepção luminosa (nula) a conta-dedos. A avaliação pósoperatória (mínimo de 9 meses) demonstrou que em 49,1\% dos casos não houve alteração da acuidade visual, 40,6\% pioraram e em 10,1\% houve melhora (Quadro 1).

À biomicroscopia, todos os pacientes apresentaram infiltrado corneal. Perfuração estava presente em 55,9\% dos casos e os demais apresentavam afinamento importante, com risco de perfuração.

Foi feita ultra-sonografia antes da cirurgia em todos os pacientes, dos quais $51(86,4 \%)$ não apresentaram alterações, $5(8,4 \%)$ apresentaram descolamento de retina, $2(3,3 \%)$ alterações sugestivas de endoftalmite e $1(1,6 \%)$ descolamento de coróide. Dos cinco casos de descolamento de retina, três (duas ceratites bacterianas e uma herpética) apresentaram piora da acuidade visual no período pós-operatório, enquanto dois (uma com ceratite bacteriana e uma com cultura e/ou bacterioscopia negativa) mantiveram-se inalterados. Dentre as endoftalmites, uma era infecção mista (bacteriana e fúngica), que evoluiu para a evisceração, e a outra, com cultura e/ou bacterioscopia negativa, evoluiu para a cura.

Dentre os 59 transplantes realizados, 50 (84,7\%) foram diagnosticados como ceratite infecciosa (bacteriana ou fúngica) e $9(15,2 \%)$ como ceratite herpética. Dentre os 50 casos de ceratites infecciosas (bacteriana ou fúngica), $42 \%$ eram bacterianas, $8 \%$ fúngicas, $8 \%$ mistas e em $42 \%$ não foi identificado o agente (Tabela 1 ).

Dos 50 casos em que foi coletado material para cultura e/ou bacterioscopia, 58,0\% mostraram resultado positivo, dos quais $86,2 \%$ eram bacterianos e $27,5 \%$ eram fúngicos.

Ceratite bacteriana: das bactérias isoladas pela cultura, o Streptococcus sp e o Staphylococcus sp apresentaram maior número, cinco casos cada. Pseudomonas aeruginosa foi isolada em três casos e Morganella morganii em um caso. Pela bacterioscopia foram identificadas nove bactérias gram positivas e duas gram negativas.

Ceratite fúngica: pela cultura, foi possível identificar um caso de Candida sp e um caso de Trychophyton sp. Oito casos de levedura foram identificados na bacterioscopia.

Foi possível coletar os dados do tamanho da trepanação do botão doador e do leito receptor em 38 prontuários dos 59 revisados. A média do tamanho do botão doador foi de $8,2 \mathrm{~mm}$ $\pm 1,1$ (variou de 5 a $10 \mathrm{~mm}$ ) e a do leito receptor foi de $7,4 \mathrm{~mm} \pm$ 1,0 (variou de 5 a 9,75 mm). Transparência do botão corneal transplantado (mínimo de 9 meses) foi observada em 1 paciente dentre todos os submetidos ao transplante terapêutico. 


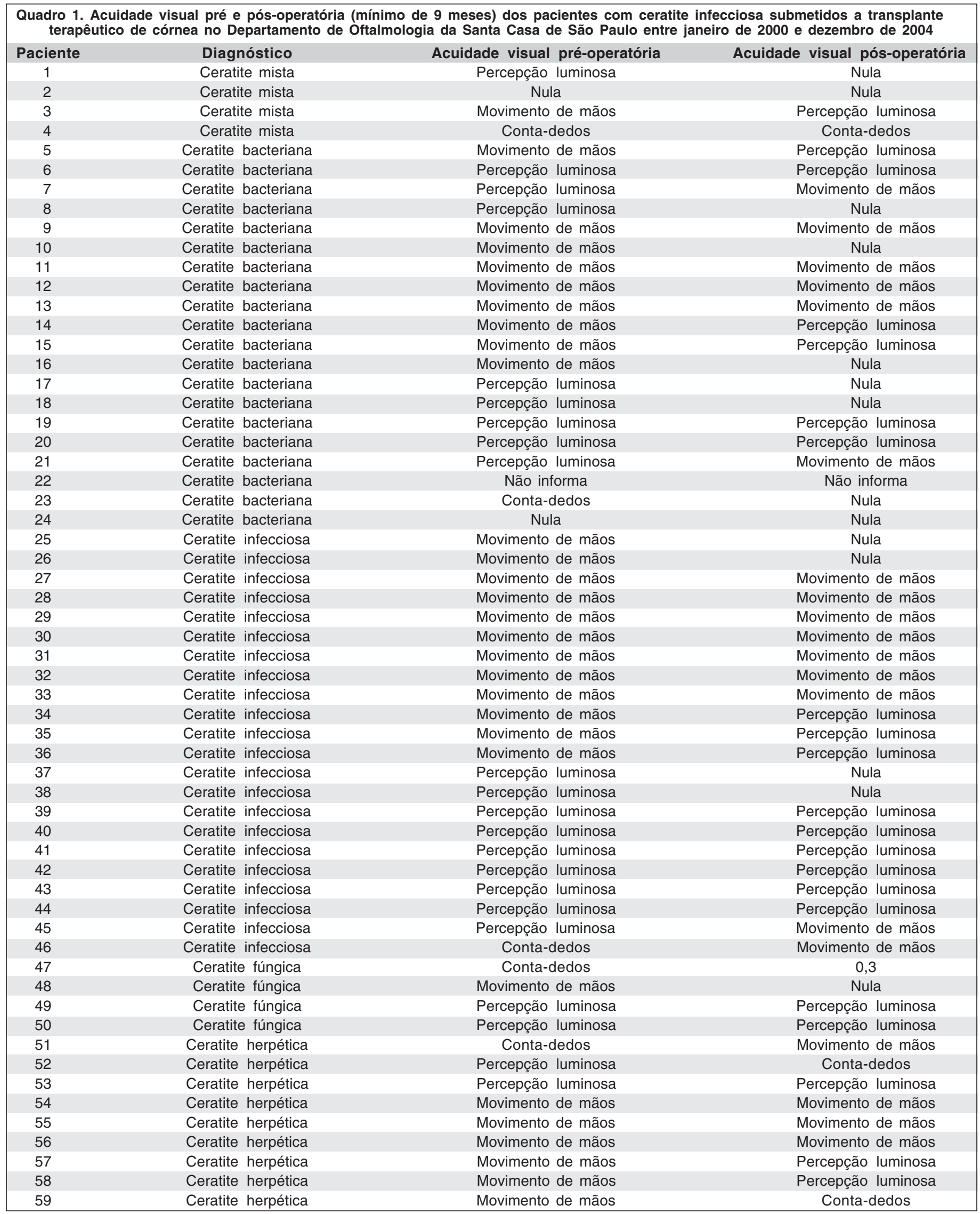


Sucesso do transplante, incluindo a erradicação da infecção e o restabelecimento da integridade do bulbo ocular, foi obtido em $89,8 \%$ dos pacientes. Dentre as ceratites bacterianas, o sucesso foi de $95,2 \%$; nas fúngicas de $100 \%$; nas mistas de $25 \%$ e, nas com cultura e/ou bacterioscopia negativas, foi de $95,2 \%$. Nas ceratites herpéticas, o sucesso foi de $100 \%$ (Quadro 2).

Dentre as complicações do período pós-operatório, foram encontrados dois casos de rejeição, seis de recidiva da infecção, treze de aumento da pressão intra-ocular e um de perfuração (Quadro 3).

Dos seis casos $(10,1 \%)$ de recidiva da infecção no botão corneal transplantado, cinco foram eviscerados, dentre eles duas ceratites mistas (uma endoftalmite), duas ceratites com cultura e/ou bacterioscopia negativa, sendo uma perfurada, e uma ceratite bacteriana. Uma recidiva de ceratite mista foi submetida a retransplante com sucesso.

\begin{tabular}{|lcc|}
\hline \multicolumn{3}{|c|}{$\begin{array}{l}\text { Tabela 1. Identificação do agente agressor das ceratites infecciosas } \\
\text { (bacteriana ou fúngica) }\end{array}$} \\
pela cultura e/ou bacterioscopia
\end{tabular}

\begin{tabular}{|lcc|}
\hline \multicolumn{4}{|l|}{ Quadro 2. Índice de sucesso dos transplantes terapêuticos de } \\
\multicolumn{4}{|l}{ córnea realizados no Departamento de Oftalmologia da Santa Casa } \\
de São Paulo, no período entre janeiro de 2000 e dezembro de 2004 \\
Ceratite & Número & Porcentagem \\
Bacteriana & $20 / 21$ & $95,2 \%$ \\
Fúngica & $4 / 4$ & $100,0 \%$ \\
Mista (bacteriana e fúngica) & $1 / 4$ & $25,0 \%$ \\
Agente não identificado & $20 / 21$ & $95,2 \%$ \\
Herpética & $9 / 9$ & $100,0 \%$ \\
\hline
\end{tabular}

\begin{tabular}{|c|c|c|}
\hline \multicolumn{3}{|c|}{$\begin{array}{l}\text { Quadro 3. Complicações dos transplantes terapêuticos de córnea } \\
\text { realizados no Departamento de Oftalmologia da Santa Casa de São } \\
\text { Paulo, no período entre janeiro de } 2000 \text { e dezembro de } 2004\end{array}$} \\
\hline Complicações & Número & Causas \\
\hline Rejeição & 2 & $\begin{array}{l}\text { Ceratites com cultura e/ou } \\
\text { bacterioscopia negativa }\end{array}$ \\
\hline \multirow[t]{3}{*}{ Recidiva } & 1 & Ceratite bacteriana \\
\hline & 2 & $\begin{array}{l}\text { Ceratites com cultura e/ou } \\
\text { bacterioscopia negativa }\end{array}$ \\
\hline & 3 & Ceratites mistas \\
\hline Perfuração & 1 & $\begin{array}{l}\text { Ceratite com cultura e/ou } \\
\text { bacterioscopia negativa }\end{array}$ \\
\hline Aumento da pressão & 1 & Ceratite fúngica \\
\hline \multirow[t]{3}{*}{ Intra-ocular } & 1 & Ceratite mista \\
\hline & 3 & Ceratites bacterianas \\
\hline & 8 & $\begin{array}{l}\text { Ceratites com cultura e/ou } \\
\text { bacterioscopia negativa }\end{array}$ \\
\hline
\end{tabular}

\section{DISCUSSÃO}

Ceratite infecciosa é doença grave e causa comum de cegueira; portanto, necessita de tratamento imediato ${ }^{(1,4-6)}$. Recentes avanços no tratamento antimicrobiano têm melhorado o prognóstico em muitos casos e reduzido a necessidade de cirurgia de urgência ${ }^{(7)}$. Em nosso serviço, entretanto, por suas características de hospital público e de referência terciária, o maior número de casos são graves, avançados e refratários ao tratamento, de modo que o número de transplantes terapêuticos realizados $(18,4 \%)$ também é maior. Estudos mostram que transplantes terapêuticos correspondem de $2,6 \%$ a $17,9 \%$ do total de transplantes penetrantes realizados ${ }^{(7,20-21)}$. Muitos pacientes chegam ao nosso serviço usando vários medicamentos (antibióticos, corticóides e outros antiinflamatórios) receitados empiricamente; a maioria não foi submetida a coleta de material para avaliação microbiológica e os resultados do tratamento clínico são limitados. Além disso, com a melhora da técnica de cirurgia, de material cirúrgico e da maior disponibilidade de córneas, muitos casos, que no passado eram eviscerados ou enucleados, podem atualmente ser recuperados com o transplante terapêutico de córnea.

Assim como no estudo de alguns autores as ceratites bacteriana e fúngica foram indicações mais freqüente de transplante terapêutico do que a ceratite herpética ${ }^{(1)}$.

Em nosso estudo, foi possível a identificação do agente (cultura e/ou bacterioscopia) em 58\% das ceratites bacterianas e fúngicas. Outros autores obtiveram resultado positivo em $70 \%{ }^{(3)}$. O uso prolongado de antibióticos em dose inadequada para tratamento de infecções, sem a prévia coleta de material para pesquisa laboratorial, pode contribuir para diminuir a possibilidade de identificação do agente agressor.

Bactérias gram positivas, Streptococcus sp e Staphylococcus $\mathrm{sp}$, cada uma com cinco casos $(23,8 \%)$ de 21 bactérias isoladas, foram os agentes mais encontrados, seguidos pela Pseudomonas sp com três casos (14,3\%). No estudo de 108 olhos submetidos a transplante terapêutico, Pseudomonas aeruginosa foi o agente mais comum $(51,2 \%)$, geralmente associado ao uso de lente de contato $^{(7)}$. Pseudomonas sp também foi o agente mais freqüente na série de casos apresentada por outros autores ${ }^{(22)}$. Considerado agente de alta virulência devido a sua rápida ação de destruição, espera-se maior número de infecções graves causadas por Pseudomonas sp do que por bactéria gram positiva. Entretanto, recebemos em nosso serviço muitos casos graves e crônicos e infecções por agentes oportunistas e resistentes, o que poderia explicar o maior número de transplante terapêutico nas infecções por Staphylococcus sp e Streptococcus $\mathrm{sp}^{(5)}$. Assim como no estudo de outros autores, Staphylococcus sp também foi a bactéria mais freqüente (33,3\%), seguida pela Pseudomonas aeruginosa $(13,3 \%)$ e Streptococcus $\mathrm{sp}(13,3 \%)^{(3)}$.

Considerando como sucesso a erradicação da infecção e o restabelecimento da integridade do bulbo ocular, $89,8 \%$ dos casos avaliados foram bem sucedidos. Dentre os pacientes com ceratites bacterianas, o índice de sucesso foi de $95,2 \%$. 
Daqueles com ceratites fúngica e herpética encontramos índice de sucesso de $100 \%$. Nas formas mistas $25 \%$ e $95,2 \%$ naquelas nas quais não foi possível a identificação do agente. Estudos anteriores têm também mostrado resultados semelhantes, com índices menores de sucesso nas infecções mistas, possivelmente devido à maior eficácia dos antimicrobianos específicos nas ceratites bacterianas ou fúngicas isoladas em comparação com as associações de agentes ${ }^{(9)}$.

Transplante terapêutico na ceratite fúngica tem usualmente mau prognóstico. Em nosso estudo, assim como em outros estudos, o resultado foi surpreendentemente bom e não houve recidiva da infecção em nenhum caso, possivelmente devido à lavagem da câmara anterior com antifúngico e manutenção da terapia antimicótica após a cirurgia ${ }^{(2,9)}$.

Ceratite herpética foi responsável por 15,2\% (nove casos) das indicações de transplante terapêutico de córnea. Não houve recidiva em nenhum caso. Todos os pacientes foram submetidos à profilaxia sistêmica com aciclovir $800 \mathrm{mg}$ ao dia, por período mínimo de seis meses após a cirurgia ${ }^{(1,9,11-13)}$.

Assim como no estudo de alguns autores, também não houve recidiva em nenhum dos 13 pacientes com ceratite herpética inativa submetidos a transplante penetrante de córnea, tratados profilaticamente por seis meses com $800 \mathrm{mg}$ de aciclovir oral. No grupo controle não tratado com aciclovir, houve recidiva em $44 \%$ dos $\operatorname{casos}^{(23)}$.

Em nosso estudo, encontramos dois casos de endoftalmites, dos quais um evoluiu para evisceração e outro para cura. Ambos os casos foram submetidos à vitrectomia a céu aberto e injeção intravítrea de antibiótico e/ou antifúngico, associada ao transplante terapêutico. Diferentemente, no estudo apresentado por outros autores, das sete endoftalmites tratadas com o mesmo procedimento cirúrgico, todas obtiveram sucesso ${ }^{(1)}$.

Enquanto estudos prévios têm demonstrado alta porcentagem de córneas transplantadas transparentes em até um ano de seguimento pós-operatório e correlacionado a transparência com o tamanho do botão corneal, ou seja, enxertos maiores associados a pior prognóstico devido ao risco maior de desenvolver sinéquias anteriores periféricas, rejeição, vascularização, glaucoma e córnea opaca ${ }^{(1,7)}$ em nosso estudo apenas um caso (pós ceratite herpética) apresentou botão corneal claro. Devido à pequena quantidade de doações de córnea que temos diante da procura de pacientes que necessitam de transplante de córnea, quando o transplante deve ser realizado com urgência (finalidade terapêutica e tectônica), temos de trabalhar com córneas classificadas como razoáveis, ou seja, córneas com baixa contagem de células endoteliais e com opacidades. Uma vez que a maior parte das córneas transplantadas não eram adequadas para transplante óptico, não foi possível correlacionar o grau de transparência do botão corneal com o seu tamanho.

Mesmo com córneas opacas, houve melhora da acuidade visual final em seis pacientes $(10,2 \%)$ e piora em $24(40,7 \%)$, possivelmente devido à opacidade maior final. Mesmo com lesões corneais perfuradas ou com afinamentos, a acuidade visual pode ser relativamente boa, se a lesão for periférica.
A trepanação do botão doador foi feita 0,25 a $1,0 \mathrm{~mm}$ maior que o leito receptor para prevenir sinéquias periféricas e aumento da pressão intra-ocular no período pós-operatório, o que também justifica realização de uma ou múltiplas iridectomias.

Foi evitada a sutura contínua, pois a cicatrização em olhos inflamados pode ser desigual. Além disso, os pontos separados permitem melhor coaptação das bordas, já que foi realizada a trepanação a mão-livre.

Dos 59 pacientes submetidos a transplante terapêutico, seis apresentaram recidiva da infecção, dos quais cinco foram eviscerados e um foi submetido a retransplante com sucesso.

Em outros dois estudos ocorreram cinco casos de recidiva e todos foram eviscerados. Em ambos os estudos, a evisceração foi indicada após tratamento máximo com medicamentos e procedimentos cirúrgicos, sem melhora da infecção ${ }^{(7,9)}$.

No nosso estudo, $22 \%$ dos pacientes apresentaram aumento da pressão intra-ocular no período pós-operatório, resultado semelhante com os de pacientes submetidos a transplante óptico, em que o aumento da pressão intra-ocular ocorreu em $21,5 \%$ dos casos, assim como em outro estudo, 31,7\% (24-25).

\section{CONCLUSÃO}

Diante dos resultados, podemos concluir que o transplante terapêutico deve ser considerado uma importante alternativa para a erradicação da infecção e restabelecimento da integridade do bulbo ocular nos casos de ceratite infecciosa ou herpética perfuradas ou com risco de perfuração e que não respondem ao tratamento clínico conservador. Em razão do seu caráter emergencial, mesmo com pouca melhora da acuidade visual, o simples reestabelecimento da integridade do bulbo ocular o coloca como ferramenta cirúrgica de primeira escolha nessas circunstâncias.

\section{ABSTRACT}

Purpose: To describe the results of therapeutic penetrating keratoplasty in patients with impending perforation or perforated infectious keratitis. Methods: Fifty-nine charts of patients with infectious keratitis who were submitted to therapeutic penetrating keratoplasty were retrospectively reviewed at the Department of Ophthalmology of the Santa Casa of São Paulo from January 2000 to December 2004. Pre- and post operative visual acuity, biomicroscopy, echography, culture and bacterioscopy were analyzed. Patients with a minimum 9month follow-up were included and were divided into 5 groups: herpetic, bacterial, fungal, bacterial-fungal keratitis and keratitis with negative culture bacterioscopy. Results: Erradication of infection and restoration of ocular integrity were obtained in $95.2 \%$ of all bacterial keratitis; $100 \%$ fungal; $25.0 \%$ bacterial-fungal; $95.2 \%$ negative culture and $100 \%$ of all herpetic keratitis. Complications included: 2 rejections, 6 recurrences, 13 glaucomas and 1 perforation. Conclusion: In 
infectious keratitis with perforation or impending perforation that did not respond to conservative clinical therapy, therapeutic penetrating keratoplasty must be considered an alternative to erradicate infection and restore the ocular integrity.

Keywords: Corneal transplantation; Keratoplasty, penetrating; Keratitis/surgery; Keratitis/microbiology; Visual acuity; Eye infections/surgery

\section{REFERÊNCIAS}

1. Killingsworth DW, Stern GA, Driebe WT, Knapp A, Dragon DM. Results of therapeutic penetrating keratoplasty. Ophthalmology. 1993;100(4):534-41.

2. Sato EH, Belfort Jr R. Tratamento cirúrgico da ceratites infecciosas. In: Kara-José N, Belfort Jr R. Córnea cirúrgica: clínica. São Paulo: Roca; 1997. p.505-11.

3. Miedziak AL, Miller MR, Rapuano CJ, Laibson PR, Cohen E.J. Risk factors in microbial keratitis leading to penetrating keratoplasty. Ophthalmology. 1999;106(6):1166-70; discussion 1171.

4. Foster RK, Rebell G. Therapeutic surgery in failures of medical treatment for fungal keratitis. Br J Ophthalmol. 1975;59(7):366-71.

5. Hill JC. Use of penetrating keratoplasty in acute bacterial keratitis. $\mathrm{Br} \mathrm{J}$ Ophthalmol. 1986;70(7):502-6.

6. Malik SR, Singh G. Therapeutic keratoplasty in Pseudomonas pyocyaneus corneal ulcers. Br J Ophthalmol. 1971;55(5):326-30.

7. Chen WL, Wu CY, Hu FR, Wang IJ. Therapeutic penetrating keratoplasty for microbial keratitis in Taiwan from 1987 to 2001. Am J Ophthalmol. 2004;137 (4):736-43.

8. Panda A, Khokhar S, Rao V, Das GK, Sharma N: Therapeutic penetrating keratoplasty in nonhealing corneal ulcer. Ophthalmic Surg. 1995;26(4):325-9.

9. Sukhija JM, Jain AK. Outcome of therapeutic penetrating keratoplasty in infectious keratitis. Ophthalmic Surg Lasers Imaging. 2005;36(4):303-9.

10. Panda A, Vajpayee RB, Kumar TS. Critical evaluation of therapeutic keratoplasty in cases of keratomycosis. Ann Ophthalmol. 1991;23(10):373-6.
11. Polack FM, Kaufman HE, Newmark E. Keratomycosis: medical and surgical treatment. Arch Ophthalmol. 1971;85(4):410-6.

12. Van Rooij J, Rijneveld WJ, Remeijer L, Volker-Dieben HJ, Eggink CA, Geerards AJ, et al. Effect of oral acyclovir after penetrating keratoplasty for herpetic keratitis: a placebo-controlled multicenter trial. Ophthalmology. 2003;110(10):1916-9; discussion 1919.

13. Araújo ME, Santos NC, Freitas D. Transplante de córnea em ceratite por Herpes simples. Arq Bras Oftalmol. 2002;65(5):515-8.

14. Foster CS, Duncan J. Penetrating keratoplasty for herpes simplex keratitis. Am J Ophthalmol. 1981;92(3):336-43.

15. Polack FM, Kaufman HE. Penetrating keratoplasty in herpetic keratitis. Am J Ophthalmol. 1972;73(6):908-13.

16. Sony P, Sharma N, Vajpayee RB, Ray M. Therapeutic keratoplasty for infectious keratitis: a review of the literature. CLAO J. 2002;28(3):111-8.

17. Yao YF, Zhang YM, Zhou P, Zhang B, Qiu WY, Tseng SC. Therapeutic penetrating keratoplasty in severe fungal keratitis using cryopreserved donor corneas. Br J Ophthalmol. 2003;87(5):543-7.

18. Xie L, Dong X, Shi W. Treatment of fungal keratitis by penetrating keratoplasty. Br J Ophthalmol. 2001;85(9):1070-4.

19. Lomholt JA, Baggesen K, Ehlers N. Recurrence and rejection rates following corneal transplantation for herpes simplex keratitis. Acta Ophthalmol Scand. 1995;73(1):29-32.

20. Chen WL, Hu FR, Wang IJ. Changing indications for penetrating keratoplasty in Taiwan from 1987 to 1999. Cornea. 2001;20(2):141-4.

21. Cursiefen C, Kuchle M, Naumann GO. Changing indications for penetrating keratoplasty; histology of 1.250 corneal buttons. Córnea. 1998;17(5):468-70.

22. Hayashi S, Sato EH, Freitas D, Lottenberg CL, Ferraz JM, Nosé W. Transplante terapêutico em úlceras de córnea bacterianas ativas. Arq Bras Oftalmol. 1991;54(2):73-8.

23. Barney NP, Foster CS. A prospective randomized trial of oral acyclovir after penetrating keratoplasty for herpes simplex keratitis. Cornea. 1994;13(3):232-6.

24. França ET, Arcieri ES, Arcieri RS, Rocha FJ. A study of glaucoma after penetrating keratoplasty. Cornea. 2002;21(3):284-8. Comment in: Cornea. 2003;22(1):91; author reply 91-2.

25. Endriss D, Cunha F, Ribeiro MP \& Toscana J: Ceratoplastias penetrantes realizadas na Fundação Altino Ventura: revisão dos resultados e complicações. Arq Bras Oftalmol. 2003;66(2):273-7. 